Article

\title{
Estimation of Canopy Water Content by Means of Hyperspectral Indices Based on Drought Stress Gradient Experiments of Maize in the North Plain China
}

\section{Feng Zhang ${ }^{1}$ and Guangsheng Zhou ${ }^{2, *}$}

1 State Key Laboratory of Vegetation and Environmental Change, Institute of Botany, Chinese Academy of Sciences, Beijing 100093, China; E-Mail: zhangfeng@ibcas.ac.cn

2 Chinese Academy of Meteorological Sciences, Beijing 100081, China

* Author to whom correspondence should be addressed; E-Mail: gszhou@ cams.cma.gov.cn; Tel.: +86-10-6840-9148; Fax: +86-10-6217-5931.

Academic Editors: Pablo J. Zarco-Tejada, Clement Atzberger and Prasad S. Thenkabail Received: 17 August 2015 / Accepted: 3 November 2015/ Published: 12 November 2015

\begin{abstract}
Here, we conducted drought stress gradient experiments of maize, and used ten water content related vegetation indices (VIs) to estimate widely variable canopy water content $(C W C)$ and mean leaf equivalent water thickness at canopy level $(\overline{E W T})$ based on in situ measurements of Lambertian equivalent reflectance and important biological and environmental factors during the 2013-2014 growing seasons in the North China Plain. Among ten VIs, the performances of green chlorophyll index (CIgreen), red edge chlorophyll index ( $\left.\mathrm{CI}_{\text {red edge }}\right)$, and the red edge normalized ratio $\left(\mathrm{NR}_{\text {red edge }}\right)$ were most sensitive to the variations of $C W C$ and $\overline{E W T}$. Simulated drought in two differently managed irrigation years did not affect the sensitivities of VIs to the variations in $C W C$ and $\overline{E W T}$. However, the relationships between $C W C$ and VIs were more noticeable in 2014 than in 2013. In contrast, $\overline{E W T}$ and VIs were more closely related in 2013 than in 2014. CWC and relative soil water content $(R S W C)$ obviously exhibited a two-dimensional trapezoid space, which illustrated that $C W C$ was determined not only by soil water status but also by crop growth and stage of development. This study demonstrated that nearly half of the variation in $C W C$ explained by spectral information was derived from the variation in leaf area index (LAI).
\end{abstract}

Keywords: canopy water content; drought stress gradients; hyperspectral remote sensing; maize canopy; spectral vegetation indices 


\section{Introduction}

Vegetation water content serves as an important biophysical characteristic of terrestrial vegetation. Knowledge related to vegetation water conditions and how it varies can contribute to accurately detecting the physiological status of vegetation [1-3]. It can also provide useful information for making sound decisions related to agriculture irrigation and assist with drought monitoring assessment $[2,4,5]$. Generally, canopy water content $(C W C)$ and the mean leaf equivalent water thickness at the canopy level $(\overline{E W T})$ are widely used for describing the vegetation water status [6,7]. Since many biogeochemical processes including photosynthesis, evapotranspiration and net primary production are closely related to vegetation $C W C$ and $\overline{E W T}$ [8-10], therefore, gaining a thorough and better understanding of vegetation $C W C$ and $\overline{E W T}$ will play an important role in mapping and monitoring the conditions of terrestrial ecosystems such as environmental stress [11], wildfire potential [12] or soil moisture retrieval [13].

Remote sensing techniques provide a non-destructive, effective, and reliable method for assessing canopy biophysical variables [5]. Hyperspectral remote sensing has been widely used especially to estimate leaf area index ( $L A I)$ [14-16], fraction of absorbed photosynthetically active radiation (fAPAR) [17,18], chlorophyll content [19-22], photosynthetic parameters [23], biomass [14], and gross primary production [21,22]. In recent years, studies of vegetation water content using remote sensing techniques have received widespread attention, and have become a focus point during vegetation monitoring and parameter inversion. Currently, a few studies have been conducted on the estimation of vegetation water content using hyperspectral data [5-7,10,24,25]. In these studies, two major approaches, physically-based radiative transfer models [5,6,10,24,25] and statistical models mainly including the first derivative reflectance spectra $[6,7,25]$, spectral reflectance indices $[5,7,10,24,26]$, continuum removed spectra analysis [6,10], and full spectrum methods [26] were used.

Radiative transfer models, being functions of canopy, leaf, and soil background characteristics, had theoretically physical foundations, but they had the ill-posed nature of model inversion [27,28]. Statistical approaches, being sensor-specific and dependent on site and sampling conditions, are easy to implement [28,29]. In addition, the full spectrum methods, such as partial least squares regression, had better predictive powers for biophysical variables [30], but it suffers from the problem of over fitting [31]. Moreover, Mirzaie et al. [26] also estimated vegetation water content by using all possible band combinations of vegetation indices (VIs) and obtained satisfactory results. Here, in the present study, the performances of the most widely used VIs were evaluated to predict $C W C$ and $\overline{E W T}$ so that these standard VIs could be linked with satellite data for applications at broader temporal and spatial scales.

Drought stress gradient experiments are effective platforms for constructing a universal algorithm for accurately estimating a wide dynamic range of $C W C$. This algorithm needs to consider both the saturation of VIs at moderate to high vegetation conditions and the adaptation of estimation models using VIs in cases of sparse canopies. This study used spectral reflectance and important biological and environmental measurements from maize drought stress gradient experiments conducted during the growing seasons in 2013-2014. The goals were to: (i) compare and evaluate the accuracy of ten VIs in estimating $C W C$ and $\overline{E W T}$ along soil moisture gradients during the entire growing season for maize; (ii) test whether two years of different irrigation management techniques can significantly affect the relationships between VIs and $C W C$ and $\overline{E W T}$; (iii) determine whether a robust algorithm for widely variable $C W C$ and $\overline{E W T}$ can be devised; and (iv) to assess the performance of hyperspectral remote 
sensing data for monitoring the seasonal variations of $C W C$ and $\overline{E W T}$. This study was conducted to select the most sensitive VIs to the variations of $C W C$ and $\overline{E W T}$, to construct a universal algorithm for the accurate estimations of $C W C$ and $\overline{E W T}$, and ultimately to evaluate the performances of VIs for monitoring crop canopy water status for maize.

\section{Materials and Methods}

\subsection{Study Area}

Experiments on responses of maize to drought stress gradients were conducted during 2013-2014 in a large water-controlled experimental field at Gucheng Ecological and Agricultural Research Station $\left(39^{\circ} 08^{\prime} \mathrm{N}, 115^{\circ} 40^{\prime} \mathrm{E}, 15.2 \mathrm{~m}\right.$ a.s.1.), Chinese Academy of Meteorological Sciences, in Dingxing County, Hebei Province, China. The warm-temperate continental monsoon climate provides a mean annual air temperature and precipitation of $11.7^{\circ} \mathrm{C}$ and $551.5 \mathrm{~mm}$, respectively. The typical brown soil had an organic matter content of $12.1 \mathrm{~g} \cdot \mathrm{kg}^{-1}$ and total nitrogen of $0.56 \mathrm{~g} \cdot \mathrm{kg}^{-1}$ [32]. This study area is located in a typical irrigation agriculture region in the North China Plain. The dominant cropping system in this region is a double cropping system of winter wheat and especially maize. The selected crop type was maize and the maize hybrid was Zheng Dan 958, sown in late June and harvested in early October. This study employed $2 \times 4 \mathrm{~m}$ experimental plots with natural field soil; each plot was equipped with a $3 \mathrm{~m}$ deep concrete wall to avoid horizontal water exchange, and also a buffer at a depth of $3 \mathrm{~m}$ to avoid vertical water exchange (Figure 1). Large electric rain-out shelters were used to exclude rainfall, so that the water supply could be artificially controlled for crop growth and development [33].

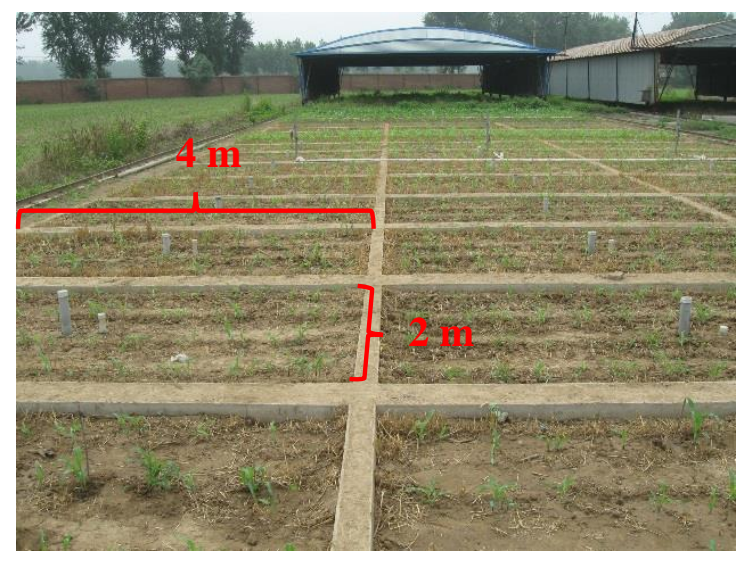

Figure 1. Photo $2 \times 4 \mathrm{~m}$ experimental plots and large electric precipitation control shelters at Gucheng Ecological and Agricultural Research Station, Chinese Academy of Meteorological Sciences, Dingxing County, Hebei Province, China.

\subsection{Experimental Design and Treatments}

Prior to the irrigation treatments using water gradients, a small amount of appropriate irrigation was conducted to maintain a consistent background level of soil water in all plots; after this initial irrigation, aside from the irrigation methods described below, the maize was never irrigated. In 2013, seven different amounts were applied to various plots for water irrigation treatments numbered 1 to 7 (120, $100,80,60,40,25$, and $15 \mathrm{~mm})$. This was completed on 24 July 2013 at the seven-leaf stage of maize 
after observations on 23 July 2013. In addition, corresponding rainfed plot controls with no irrigation and a rainfed field control were designed. The first measurements after irrigation were conducted on 29 July 2013, and only in irrigation treatments $1(120 \mathrm{~mm})$ and $2(120 \mathrm{~mm})$ were re-wetted with the amounts of $80 \mathrm{~mm}$ and $40 \mathrm{~mm}$ on 26 August 2013 after field measurements on 25 August 2013 at the flowering stage in maize, respectively (Table 1). In 2014, seven water treatments from 1 to 7 were conducted with each treatment to simulate different irrigation amounts $(225,150,120,90,60,30$, and $10 \mathrm{~mm})$ and the corresponding rainfed plot control with no irrigation was also designed on 1 July 2014; in this case, no field control was employed (Table 1). Three replicates were conducted during the experiments, with each plot being one replicate in both 2013 and 2014. In total, 24 experimental plots were constructed: seven with water gradients for 21 plots plus three control plots as well as a field control in 2013. Similarly, 24 experimental plots were also constructed in 2014 but without a field control.

Table 1. Experimental design and irrigation amounts (mm) in 2013 and 2014.

\begin{tabular}{cccccccccc}
\hline Year & Control Plot & Treat. 1 & Treat. 2 & Treat. 3 & Treat. 4 & Treat. 5 & Treat. 6 & Treat. 7 & Field Control \\
\hline 2013 & 0 & $120+80$ & $100+40$ & 80 & 60 & 40 & 25 & 15 & 0 \\
2014 & 0 & 225 & 150 & 120 & 90 & 60 & 30 & 10 & - \\
\hline
\end{tabular}

Treat. is the abbreviation for treatment and "+" indicates rewetting irrigation.

\subsection{Field Measurements}

\subsubsection{Canopy Spectral Reflectance}

A total of sixteen sets of field reflectance spectra measurements were made on a nearly weekly basis during July-October as follows: 23 and 30 July, 8, 18 and 25 August, 5 and 20 September, and 8 October in 2013, and 10 and 18 July, 1, 7 and 19 August, 3, 16 and 27 September in 2014 (Table 2). An ASD FieldSpec3 spectroradiometer (Analytical Spectral Devices, Boulder, CO, USA) was used to measure spectral reflectance (details in [18]). Spectral measurements were made on days with clear skies between $11 \mathrm{~h}$ and $14 \mathrm{~h}$. The fiber optics, with a field of view of $25^{\circ}$, were handheld approximately $1-1.3 \mathrm{~m}$ above the undisturbed maize canopy at the nadir position at each experimental plot for every observation during the growing seasons of 2013-2014 as well as for the field control in 2013. Each water treatment was replicated three times and with 20 spectral readings for each spectral measurement above the maize canopy per experimental plot. The mean value of spectral reflectance averaged over these 20 spectral measurements was used as the spectral reflectance of each experimental plot. During spectral measurements, a standard white spectralon target with a reflectance of 0.99 was placed on the ground next to the experimental plots and was used as a reference against which the target objects could be calibrated. Thus, the reflectance values became dimensionless.

Table 2. Field reflectance spectra measurement dates in 2013 and 2014.

\begin{tabular}{ccccccccc}
\hline Year & NO.1 & NO.2 & NO.3 & NO.4 & NO.5 & NO.6 & NO.7 & NO.8 \\
\hline 2013 & 23 July & 30 July & 8 August & 18 August & 25 August & 5 September & 20 September & 8 October \\
2014 & 10 July & 18 July & 1 August & 7 August & 19 August & 3 September & 16 September & 27 September \\
\hline
\end{tabular}




\subsubsection{CWC}

We made three replicates for each irrigation treatment, and used one standard maize plant per experimental plot as well as 3-4 standard plants for the field control, and harvested these plants to measure fresh weight $\left(F W, \mathrm{~g} \cdot \mathrm{m}^{-2}\right)$ and dry weight $\left(D W, \mathrm{~g} \cdot \mathrm{m}^{-2}\right)$ for leaves, stems, and fruit. The area-coefficient method was used to measure $L A I$ [18]. In this study, only one standard plant per plot was harvested, and its individual lengths and widths were measured on each sampling date. Observation dates of biomass and $L A I$ were the same as for the spectral reflectance measurements. Using the dates listed above, eight data collection campaigns per year were conducted, with sixteen campaigns in total.

At the canopy level, $C W C$ can be defined as the quantity of water per unit area of ground surface $\left(\mathrm{g} \cdot \mathrm{m}^{-2}\right)$ [34]. $C W C$ is calculated by $\overline{E W T}$, defined as quantity of water per unit leaf area $\left(\mathrm{g} \cdot \mathrm{cm}^{-2}\right)$ [35], multiplied by the canopy $L A I$ or the difference between $F W$ and $D W$. In this study, $C W C$ was the quantity of canopy leaf water in maize per unit area of ground surface calculated by Equation (1). Additionally, the canopy level reflectance is usually affected by $L A I$ and a large variability in $L A I$ will enhance water content related features in spectral reflectance, and thus improve the estimation accuracy of $C W C$. Therefore, to evaluate the effects of $L A I$ on water content related VIs for the estimation of $C W C$, we also calculated $\overline{E W T}$ by Equation (2):

$$
\begin{aligned}
& C W C=F W-D W \\
& \overline{E W T}=C W C / L A I
\end{aligned}
$$

\subsubsection{Soil Water Content}

After the spectral measurements, gravimetric soil moisture $\left(\theta_{\mathrm{m}}, \%\right)$ was measured by oven-drying soil samples at $105^{\circ} \mathrm{C}$ for $24 \mathrm{~h}$ for controlled-gradient plots, as well as for the corresponding plot and field controls. Every $10 \mathrm{~cm}$ soil layer was sampled for $0-50 \mathrm{~cm}$ soil profiles in 2013 and $0-90 \mathrm{~cm}$ in 2014 , with three replicates for one water treatment and one sampling per plot. In addition, four observation sites were used for the field control with one replicate for each observation site in 2013. Relative soil water content $(R S W C, \%)$ was the ratio of $\theta_{\mathrm{m}}$ and field capacity $\left(F_{\mathrm{c}}\right.$; Equation $\left.(3)\right)$ :

$$
R S W C=\left(\theta_{\mathrm{m}} / F_{\mathrm{c}}\right) \times 100 \%
$$

In this study, the roots of maize penetrated about $30 \mathrm{~cm}$. Therefore, the mean values of $R S W C$ were averaged over three values at 10,20 and $30 \mathrm{~cm}$ soil depth represented the $R S W C$ value of each experimental plot.

\subsection{Vegetation Indices Used in This Analysis}

We describe ten water content related VIs with the goal of examining their potential of estimating widely variable $C W C$ and $\overline{E W T}$ (Table 3 [4,19,36-41]). 
Table 3. Vegetation indices (VIs) used in the study and related source references.

\begin{tabular}{|c|c|c|}
\hline Index & Equation & Reference \\
\hline Normalized difference vegetation index (NDVI) & $\left(\rho_{n i r}-\rho_{r e d}\right) /\left(\rho_{n i r}+\rho_{r e d}\right)$ & {$[36]$} \\
\hline Red edge normalized ratio ( $\left.\mathrm{NR}_{\text {red edge }}\right)$ & $\left(\rho_{750}-\rho_{710}\right) /\left(\rho_{750}+\rho_{710}\right)$ & {$[37]$} \\
\hline Water index (WI) & $\rho_{900} / \rho_{970}$ & {$[4]$} \\
\hline Normalized difference water index (NDWI) & $\left(\rho_{860}-\rho_{1240}\right) /\left(\rho_{860}+\rho_{1240}\right)$ & {$[38]$} \\
\hline Land surface water index (LSWI) & $\left(\rho_{\text {nir }}-\rho_{\text {swir }}\right) /\left(\rho_{\text {nir }}+\rho_{\text {swir }}\right)$ & {$[39,40]$} \\
\hline Green chlorophyll index ( $\left.\mathrm{CI}_{\text {green }}\right)$ & $\left(\rho_{750} / \rho_{550}\right)-1$ & [19] \\
\hline Red edge chlorophyll index $\left(\mathrm{CI}_{\text {red edge }}\right)$ & $\left(\rho_{750} / \rho_{710}\right)-1$ & [19] \\
\hline Normalized red edge reflectance curve area $(680-780 \mathrm{~nm}$; Area $680-780)$ & $\sum_{i=680}^{780}\left(\frac{\rho_{\alpha(i)}}{\rho_{780}}\right)$ & {$[41]$} \\
\hline Normalized reflectance curve area (1015-1050nm; Area $1015-1050)$ & $\sum_{i=1015}^{1050}\left(\frac{\rho_{\lambda(i)}}{\rho_{1050}}\right)$ & This study \\
\hline Normalized reflectance curve area $\left(1110-1170 \mathrm{~nm} ;\right.$ Area $_{1110-1170)}$ & $\sum_{i=1110}^{1170}\left(\frac{\rho_{\lambda(i)}}{\rho_{1170}}\right)$ & This study \\
\hline
\end{tabular}

Notes: $\rho_{\text {nir, }} \rho_{\text {red, }}$ and $\rho_{\text {swir }}$ are the averaged reflectance among the waveband range to match MODIS data in the near-infrared $(841-876 \mathrm{~nm})$, red $(620-670 \mathrm{~nm})$, and shortwave infrared (SWIR1: 1628-1652 nm) wavelengths, respectively.

\subsubsection{Normalized Indices}

The normalized difference vegetation index (NDVI) is the most commonly used vegetation index. It is based on the contrast between the maximum absorption in the red due to chlorophyll pigments and the maximum reflectance in the infrared caused by leaf cellular structure and LAI [30]. In addition, a red edge normalized ratio ( $\mathrm{NR}_{\text {red edge) }}$ uses the same NDVI formulation but with the red edge (around $700 \mathrm{~nm}$ ) bands. NR red edge is also a good predictor of green vegetation information [42]. Viña and Gitelson [17] used it to estimate $f A P A R$, and $\mathrm{Wu}$ et al. [36] tested $\mathrm{NR}_{\text {red edge }}$ in the remote estimation of canopy chlorophyll content.

\subsubsection{Water-Related Indices}

Studies have been conducted on VIs closely related to canopy water status. The land surface water index (LSWI) was calculated as the normalized difference between the near-infrared (NIR; 780-890 nm) and the shortwave-infrared (SWIR; $1580 \mathrm{~nm}-1750 \mathrm{~nm}$ ) wavelengths [39,40]. The water band index (WI) is the ratio between the reflectance at 900 and $970 \mathrm{~nm}$ [4]. In addition, the normalized difference water index (NDWI) used reflectance values in the $860 \mathrm{~nm}$ in the NIR region and $1240 \mathrm{~nm}$ in the SWIR1 region spectral bands of hyperspectral data [38].

\subsubsection{Chlorophyll Indices}

Vegetation water content was not only related with water information, but also had quite a close relationship with crop greenness (chlorophyll). Gitelson et al. [19] proposed the chlorophyll index of red edge ( $\mathrm{CI}_{\text {red edge }}$ ) model using a stepwise technique based on a linear regression of the model vs. total chlorophyll content in the canopy. They found a close relationship between $\mathrm{CI}_{\text {red edge }}$ and canopy

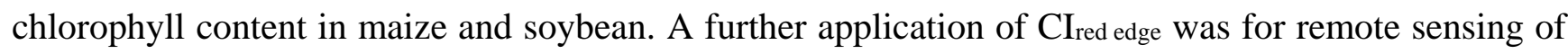
gross primary production $[19,21,22,43]$. In this study, we used both of the CIred edge and the green chlorophyll index ( $\mathrm{CI}_{\text {green }}$ ). 


\subsubsection{Normalized Reflectance Curve Area Indices}

Ren et al. [41] showed that the performance of the red-edge reflectance curve area between the normalized reflectance curve and wavelength in 680-780 $\mathrm{nm}$ region was better than that of traditional VIs and the red-edge position when used to estimate green aboveground biomass in arid and semi-arid areas. Studies showed that two water absorption features exist at approximately $970 \mathrm{~nm}$ and $1200 \mathrm{~nm}$ that were caused by the absorption by $\mathrm{O}-\mathrm{H}$ bonds in liquid canopy water [44]. Moreover, studies demonstrated that derivative spectra at the right slope of the $970 \mathrm{~nm}$ absorption feature and at the left slope of the $1200 \mathrm{~nm}$ feature had potential as predictors of $C W C$ [6]. Therefore, we not only introduced the normalized red edge reflectance curve area (680-780 nm; Area680-780), but also constructed the normalized reflectance curve area (1015-1050 nm; Area1015-1050) and the normalized reflectance curve area (1110-1170 nm; Area1110-1170). Our goal was to explore their sensitivities to the variations of $C W C$ and $\overline{E W T}$. Here, the reflectance curve area refers to an area between the reflectance curve and the horizontal coordinate axis (wavelength) in the three regions of 680-780 nm, 1015-1050 nm and 1110-1170 nm, respectively.

All statistical analyses were performed with SPSS 17.0 software (SPSS, Chicago, IL, USA), and SigmaPlot 10.0 software (Systat, San Jose, CA, USA) was used to draw the figures.

\section{Results}

\subsection{Temporal Variations of Soil Moisture, CWC and $\overline{E W T}$}

The RSWC and $C W C$ varied seasonally under different water treatments for maize during the growing seasons in 2013-2014 (Figure 2). In both years, different irrigation treatments led to significant differences of soil water status. In 2013, controlled-irrigation started on 24 July at the seven-leaf stage after observations on 23 July 2013 and RSWC gradients were observed from 29 July 2013. In 2014, early soil water control was conducted on 1 July 2014 at the three-leaf stage, and RSWC gradients were observed from 10 July 2014. In addition, the rewetting treatments with 40 and $80 \mathrm{~mm}$ were made only for treatments 1 and 2 on 26 August 2013. These rewetting treatments induced a sudden increase of $R S W C$ for these two treatments on 5 September 2014 (the first measurements after rewetting treatments), which gradually decreased later in the experiment. The status of soil water in 2013 and 2014 was similar in that a significant difference was observed among the drought-treated plots at the early stage of irrigation treatment, although these differences gradually declined over time and into the late stage of maize growth. Except for the observation dates of 23 July and 25 August for the field control in 2013, other values of $R S W C$ were basically maintained at a level above the saturated water content. Thus, it was demonstrated that different irrigation gradient treatments resulted in $R S W C$ gradients with different degrees of drought for each experimental plot. In total, compared with the soil water conditions in 2013, 2014 tended to be drier with $R S W C$ values below $40 \%$ during the middle-late stages of growth in maize. Therefore, each treatment plot basically maintained consistent and extremely dry conditions. 

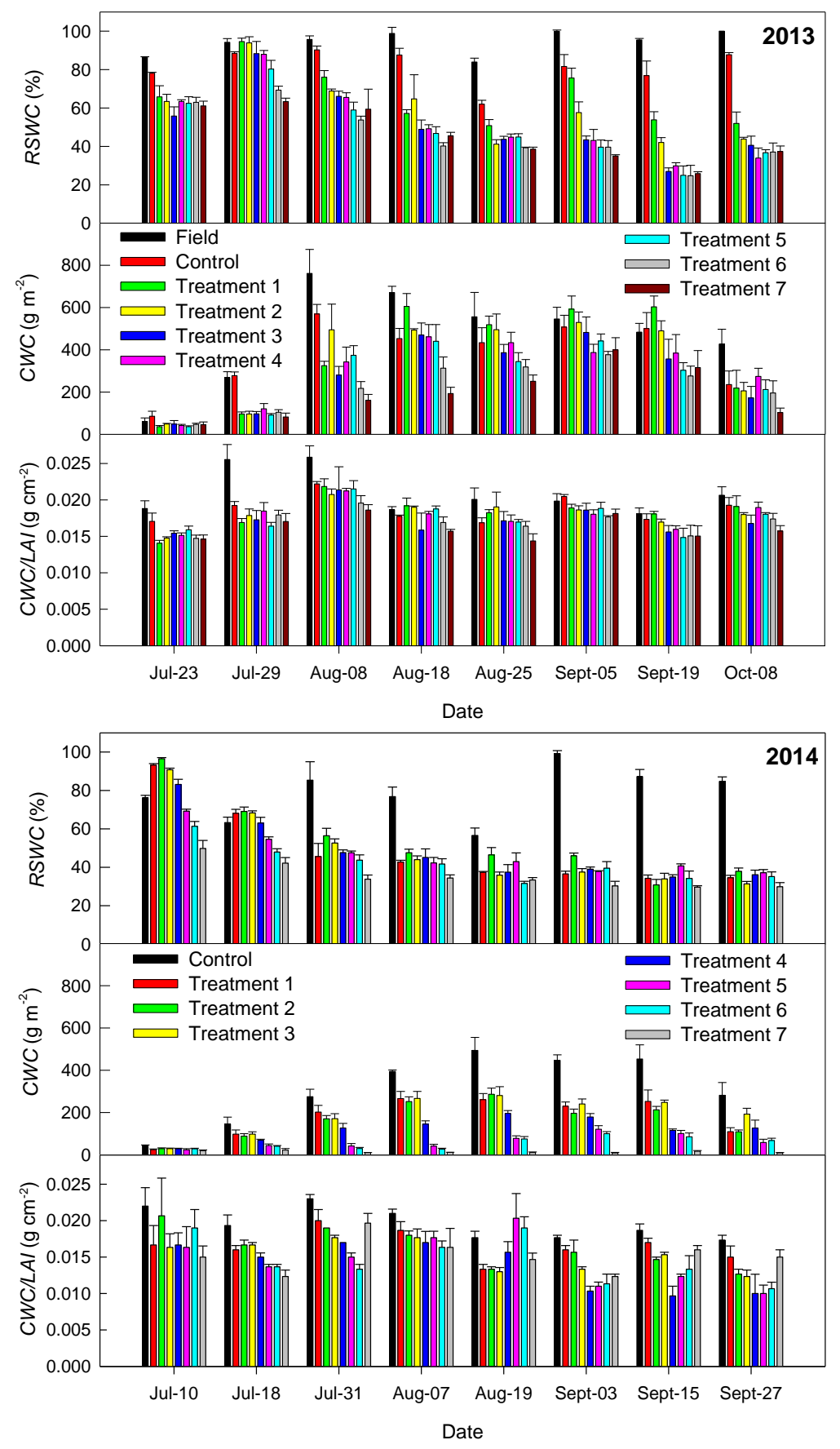

Figure 2. Variations in relative soil water content $(R S W C, \%)$, canopy water content $(C W C$, $\mathrm{g} \cdot \mathrm{m}^{-2}$ ) and mean leaf equivalent water thickness at the canopy level ( $\overline{E W T}$, i.e., $C W C /$ leaf area index $\left.(L A I), \mathrm{g} \cdot \mathrm{cm}^{-2}\right)$ during the growing seasons of 2013 and 2014. Error bars indicate the mean standard errors of three replicates. For 2013, treatments 1-7 indicate seven different irrigation amounts, 120, 100, 80, 60, 40, 25, and $15 \mathrm{~mm}$, as well as a rainfed plot control with no irrigation (Control) and a rainfed field control (Field); for 2014, treatments 1-7 indicate different irrigation amounts of $225,150,120,90,60,30$, and $10 \mathrm{~mm}$ and the rainfed plot control with no irrigation (Control).

Compared with $C W C$ and $R S W C$, the seasonal trend of $\overline{E W T}$ was not obvious. However, the differences caused by the drought gradient were remarkable (Figure 2). In 2013, after the irrigation treatment on 24 July, improved soil water status resulted in a higher value of $\overline{E W T}$. In 2014, it followed 
this pattern during the early stage of growth in maize, but when entering into the middle-late stages, the $\overline{E W T}$ values declined with experimental plots well-supplied with water entering into the reproductive stage. For the experimental treatments of moderate or severe drought, the delayed phenological phases or not entering into the reproductive stage resulted in that $\overline{E W T}$ did not always decrease and finally reached its minimum value for each plot at the end of the 2014 growing season (Figure 2).

Obvious differences were observed among each water treatment, between 2013 and 2014, and in the seasonal variations in $C W C$. Based on measurements of $C W C$, the differences among the drought-treated plots and corresponding control plots were amplified. This not only reflected the difference of soil water background, but also illustrated the differences in plant development that resulted from differences in soil water content during the entire growing season. Although different degrees of drought-stress existed, $C W C$ showed a single peak seasonal trend, with the peak occurring around 20 August. Periods with superior soil water conditions had a more obvious single peak seasonal trend. In contrast, during drought stress the seasonal trend was less obvious and the peak values decreased or the date of the peak values was delayed (Figure 2). At an inter-annual scale, the seasonal trend of $C W C$ was consistent with $R S W C$, and crops obviously grew better in 2013 than in 2014. The overall values of $C W C$ were higher in 2013 than in 2014.

Table 4 presents the descriptive statistics of canopy biophysical characteristics. As expected, the irrigation treatments induced a wide variation in $L A I, F W, D W, C W C$, and $\overline{E W T}$. In addition, the two differently managed irrigation methods occurring at different stages for maize significantly affected maize growth and development. LAI in 2013 varied and this variation was obviously higher than the variation in 2014 (Table 4). The values of leaf $F W / D W, C W C$, and $\overline{E W T}$ were all higher in 2013 than in 2014 (Table 4). In general, compared with 2013, drought affected crop growth more in 2014.

Table 4. Summary statistics of canopy biophysical characteristics of maize acquired in situ under different irrigation treatments during the $2013(n=72)$ and $2014(n=64)$ growing seasons.

\begin{tabular}{|c|c|c|c|c|c|c|c|}
\hline $\begin{array}{c}\text { Canopy Biophysical } \\
\text { Characteristics } \\
\end{array}$ & Year & $\begin{array}{c}\text { Range } \\
\text { (Min-Max) }\end{array}$ & Mean & Median & SEM & $\begin{array}{c}\text { Std. } \\
\text { Deviation }\end{array}$ & $\mathbf{C V}$ \\
\hline \multirow{2}{*}{$L A I$ (leaf area index) } & 2013 & $0.23-3.60$ & 1.75 & 1.89 & 0.11 & 0.95 & 0.54 \\
\hline & 2014 & $0.06-2.78$ & 0.89 & 0.75 & 0.09 & 0.71 & 0.80 \\
\hline \multirow{2}{*}{$F W\left(\right.$ fresh weight, $\mathrm{g} \cdot \mathrm{m}^{-2}$ ) } & 2013 & $44.3-917.2$ & 412.2 & 414.8 & 27.9 & 236.5 & 0.57 \\
\hline & 2014 & $12.7-668.7$ & 186.0 & 143.8 & 20.0 & 160.3 & 0.86 \\
\hline \multirow{2}{*}{$D W\left(\right.$ dry weight, $\left.\mathrm{g} \cdot \mathrm{m}^{-2}\right)$} & 2013 & $7.2-206.8$ & 91.2 & 95.7 & 6.5 & 55.3 & 0.61 \\
\hline & 2014 & $3.3-174.3$ & 46.5 & 35.6 & 5.2 & 41.3 & 0.89 \\
\hline \multirow{2}{*}{$\begin{array}{l}\overline{E W T} \text { (mean leaf equivalent water } \\
\text { thickness at canopy level, } \mathrm{g} \cdot \mathrm{cm}^{-2} \text { ) }\end{array}$} & 2013 & $0.014-0.026$ & 0.018 & 0.018 & 0.00028 & 0.0024 & 0.13 \\
\hline & 2014 & $0.010-0.023$ & 0.016 & 0.016 & 0.00039 & 0.0032 & 0.20 \\
\hline \multirow{2}{*}{$C W C$ (canopy water content, $\mathrm{g} \cdot \mathrm{m}^{-2}$ ) } & 2013 & $36.9-761.4$ & 320.9 & 322.2 & 21.7 & 183.7 & 0.58 \\
\hline & 2014 & $9.4-494.4$ & 139.5 & 105.3 & 15.0 & 119.7 & 0.86 \\
\hline
\end{tabular}

SEM is the standard error of mean and CV is coefficient of variation.

\subsection{Relationships between CWC, $\overline{E W T}$ and Biophysical Properties and RSWC}

Table 5 summarizes the correlated relationships between $C W C$ and $\overline{E W T}$ with $L A I, F W, D W$, and $R S W C$ for 2013 and 2014. In 2013, CWC showed an extremely significant linear correlation with $F W$, $L A I$, and $D W$. Significant linear relationships were also observed between $C W C$ and $\overline{E W T}$ as well as 
$\overline{E W T}$ and $R S W C$. Similarly, $C W C$ had extremely significant linear relationships with $F W, D W$, and $L A I$ in 2014. However, the position of the relative importance between the relationships of $C W C$ and $D W$ and $L A I$ changed. In comparison, the relationship between $C W C$ and $D W$ in the drier year was slightly closer than that of $C W C$ and $L A I$. In addition, significant linear relationships existed between $\overline{E W T}$ and $R S W C$, but not between $C W C$ and $\overline{E W T}$. Comprehensively considering the data sets in 2013 and 2014, $C W C$ had extremely significant linear relationships with $F W, L A I, D W$, and $\overline{E W T}$; and $\overline{E W T}$ also had a significant linear relationship with $R S W C$. Although there were better water conditions in 2013 and it was relatively drier in 2014, $C W C$ was always closely correlated with $F W, L A I$, and $D W$. However, it was never significantly linearly correlated with $R S W C$. Furthermore, it is important to note that the relationship between $C W C$ and $\overline{E W T}$ varied with inter-annual eco-hydrological status. That is, $C W C$ had significant linear relationship with $\overline{E W T}$ in 2013, although it was never significantly linear correlated with $\overline{E W T}$ in 2014.

Table 5. Spearman's rank correlation coefficients between $C W C, \overline{E W T}$ and canopy biophysical variables and soil moisture during the 2013 and 2014 growing seasons.

\begin{tabular}{|c|c|c|c|c|c|}
\hline & $\begin{array}{c}\text { RSWC (Relative Soil Water } \\
\text { Content, \%) }\end{array}$ & $\overline{E W T}$ & LAI & $F W$ & $D W$ \\
\hline & & \multicolumn{4}{|c|}{$2013(n=72)$} \\
\hline $\begin{array}{l}\overline{E W T} \text { (mean leaf equivalent water } \\
\text { thickness at canopy level, } \mathrm{g} \mathrm{cm}^{-2} \text { ) }\end{array}$ & $0.441 * * *$ & & & & \\
\hline$L A I$ (leaf area index) & -0.054 & $0.360 * *$ & & & \\
\hline$F W$ (fresh weight, $\mathrm{g} \mathrm{m}^{-2}$ ) & 0.027 & $0.472 * * *$ & $0.984 * * *$ & & \\
\hline$D W\left(\right.$ dry weight, $\left.\mathrm{g} \mathrm{m}^{-2}\right)$ & -0.078 & $0.347 * *$ & $0.962 * * *$ & $0.963 * * *$ & \\
\hline \multirow[t]{2}{*}{$C W C$ (canopy water content, $\mathrm{g} \mathrm{m}^{-2}$ ) } & 0.046 & $0.514 * * *$ & $0.977 * * *$ & $0.997 * * *$ & $0.944 * * *$ \\
\hline & & \multicolumn{4}{|c|}{$2014(n=64)$} \\
\hline $\begin{array}{l}\overline{E W T} \text { (mean leaf equivalent water } \\
\text { thickness at canopy level, } \mathrm{g} \mathrm{cm}^{-2} \text { ) }\end{array}$ & $0.513 * * *$ & & & & \\
\hline$L A I$ (leaf area index) & 0.030 & -0.048 & & & \\
\hline$F W$ (fresh weight, $\mathrm{g} \mathrm{m}^{-2}$ ) & 0.113 & 0.126 & $0.977 * * *$ & & \\
\hline$D W\left(\right.$ dry weight, $\left.\mathrm{g} \mathrm{m}^{-2}\right)$ & 0.015 & 0.027 & $0.988 * * *$ & $0.987 * * *$ & \\
\hline \multirow[t]{2}{*}{$C W C$ (canopy water content, $\mathrm{g} \mathrm{m}^{-2}$ ) } & 0.143 & 0.156 & $0.970 * * *$ & $0.998 * * *$ & $0.978 * * *$ \\
\hline & & \multicolumn{4}{|c|}{ Total $(n=136)$} \\
\hline $\begin{array}{l}\overline{E W T} \text { (mean leaf equivalent water } \\
\text { thickness at canopy level, } \mathrm{g} \mathrm{cm}^{-2} \text { ) }\end{array}$ & $0.525 * * *$ & & & & \\
\hline$L A I$ (leaf area index) & 0.054 & $0.317 * * *$ & & & \\
\hline$F W$ (fresh weight, $\mathrm{g} \mathrm{m}^{-2}$ ) & 0.126 & $0.438 * * *$ & $0.987 * * *$ & & \\
\hline$D W\left(\right.$ dry weight, $\left.\mathrm{g} \mathrm{m}^{-2}\right)$ & 0.027 & $0.333 * * *$ & $0.981 * * *$ & $0.980 * * *$ & \\
\hline$C W C$ (canopy water content, $\mathrm{g} \mathrm{m}^{-2}$ ) & 0.153 & $0.466 * * *$ & $0.981 * * *$ & $0.998 * * *$ & $0.969 * * *$ \\
\hline
\end{tabular}

All correlations are significant at $* p<0.05, * * p<0.01$ level, or $* * * p<0.001$.

\subsection{Relationships between CWC, $\overline{E W T}$ and VIs}

The linear/logarithmic relationships were constructed between $C W C$ and ten VIs including the normalized indices (NDVI, NR red edge), water-related indices (WI, NDWI, LSWI), chlorophyll indices ( $\mathrm{CI}_{\text {green, }} \mathrm{CI}_{\text {red edge) }}$, and the normalized reflectance curve area indices (Area680-780, Area1015-1050, and 
Area1110-1170; Figure 3). Among them, $\mathrm{CI}_{\text {green, }}, \mathrm{NR}_{\text {red edge, }}$ Area680-780, and $\mathrm{CI}_{\text {red edge }}$ increased significantly with increasing $C W C$, and showed better sensitivities to the variation of $C W C$. The relationships between $C W C$ and Area680-780, NDVI, and LSWI could be described well by logarithmic equations. In addition, significantly linear relationships were also found between CWC and WI, LSWI, Area1015-1050, NDWI, and Area1110-1170 (Figure 3).

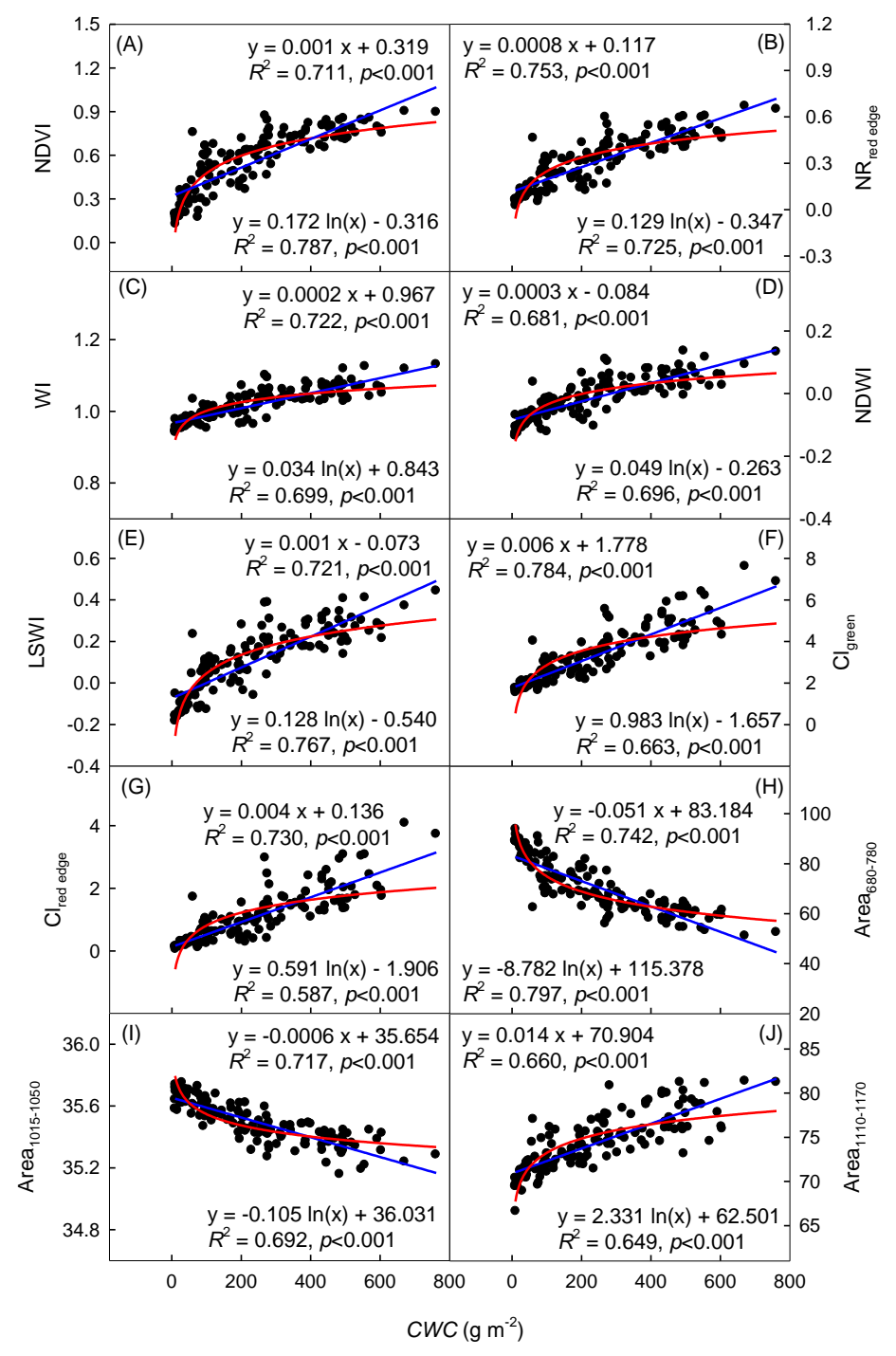

Figure 3. Relationships between (A) normalized difference vegetation index (NDVI), (B) red edge normalized ratio $\left(\mathrm{NR}_{\text {red edge }}\right),(\mathbf{C})$ water index (WI), (D) normalized difference water index (NDWI), (E) land surface water index (LSWI), (F) green chlorophyll index (CIgreen), $(\mathbf{G})$ red edge chlorophyll index $\left(\mathrm{CI}_{\text {red edge }}\right),(\mathbf{H})$ normalized red edge reflectance curve area (680-780 nm; Area680-780), (I) normalized reflectance curve area (1015-1050 nm; Area1015-1050), and (J) normalized reflectance curve area (1110-1170 nm; Area1110-1170) vs. canopy water content $(C W C)$ for maize during the growing seasons of 2013-2014.

Thus, based on the relationships between VIs and $C W C$, the ten VIs that were related to water content and tested in this study were split into three categories. The first VI type had significant linear relationships with $C W C$ instead of logarithmic ones, including $\mathrm{CI}_{\text {green, }} \mathrm{NR}_{\text {red edge, and }} \mathrm{CI}_{\text {red edge. To some }}$ degree, they could effectively overcome the saturation effects at moderate to high $C W C$ values. The 
second VI type had predominantly logarithmic relationships with $C W C$, rather than linear relationships, such as Area680-780, NDVI, and LSWI. This type of VI inevitably had saturation effects to high $C W C$ values, which were difficult to overcome. For the third VI type, the linear/logarithmic relationships had equal regression effects, and they also tended to saturate with increasing $C W C$, and included WI, Area1015-1050, NDWI, and Area1110-1170.

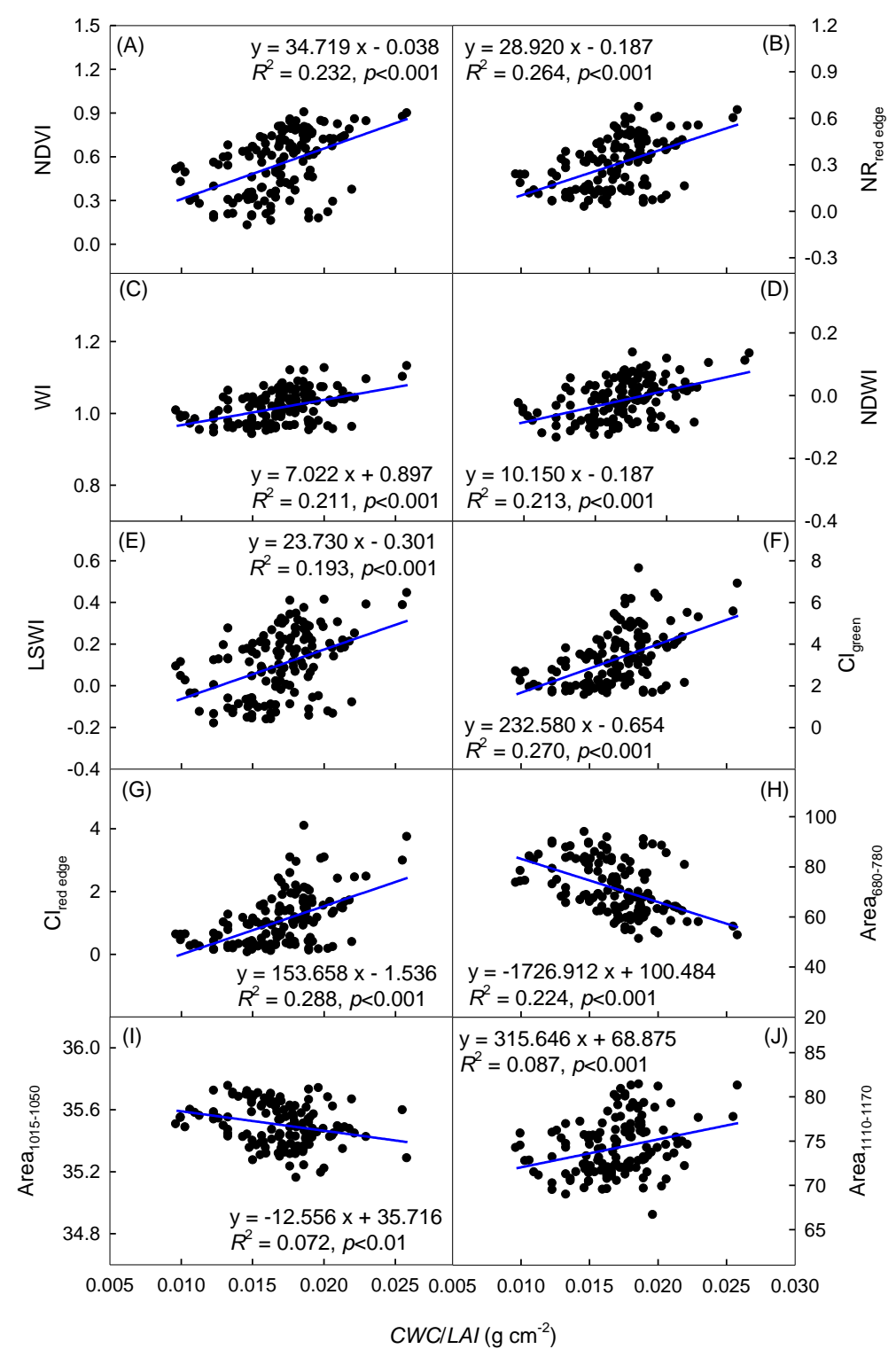

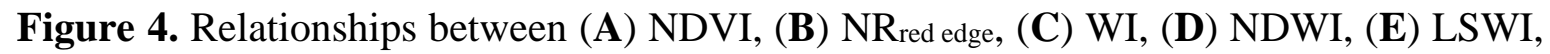
(F) CIgreen, (G) CIred edge, (H) Area680-780, (I) Area1015-1050, and (J) Area1110-1170 vs. $\overline{E W T}$ (CWC/LAI) for maize during the growing seasons of 2013-2014. Figures 2 and 3 provide the definitions of acronyms.

$C W C$ reflects not only the magnitude of the difference between $F W$ and $D W$, but also the information related to canopy architecture, i.e., LAI. To evaluate the effects of $L A I$ on water content related VIs, the linear relationships between $\overline{E W T}$ (i.e., $C W C / L A I$ ) and ten VIs were also constructed, respectively (Figure 4). Among them, CIred edge, CIgreen and NRred edge showed the most sensitivity to the variation of $\overline{E W T}$. In addition, significantly linear relationships were also found between $\overline{E W T}$ and NDVI, Area680-780, 
NDWI, WI, and LSWI (Figure 4). Figure 4 also shows that VIs had no saturation effects with increasing $\overline{E W T}$.

\section{Discussion}

\subsection{Relationships between CWC and $\overline{E W T}$ and Soil Moisture}

Figure 5 shows relationships between $C W C$ with $\overline{E W T}$ and $R S W C$ during the growing seasons of 2013 and 2014. These reflected the transfer of water stress between the soil and crop canopy, and the sensitivity of the soil and crop canopy to the variations in soil moisture when soil water conditions exhibited drought stress. Soil water was the main source of water needed for crop growth and development. No direct relationship was evident between $C W C$ and $R S W C$ (Table 5). However, soil moisture status, especially during the early stage of maize growth, is clearly a critical factor affecting the magnitude of $C W C$, which determines crop growth and development in the entire growing season. $C W C$ presented a single peak seasonal trend in 2013 and 2014; however, the overall average level in 2013 was obviously higher than the same period in 2014. This occurred because 2013 had better soil water conditions than 2014. In addition, the starting dates of irrigation gradients was later in 2013 (24 July occurred at the seven-leaf stage) than in 2014 (1 July at the three-leaf period stage). Therefore, to explore the relationship between $C W C$ and $R S W C$, not only soil moisture level, but also the starting dates of irrigation and its control levels should be comprehensively considered. When irrigation was initiated later, fewer effects were produced for crop growth and development.

$\overline{E W T}(C W C / L A I)$ could reflect available leaf water conditions at the canopy level and was closely related to plant photosynthesis and the transfer of photosynthetic matter. Figure 5 shows that $\overline{E W T}$ and $R S W C$ were significantly related in both 2013 and 2014, although the relationship between $C W C$ and $R S W C$ was not significant in both 2013 and 2014. However, when comprehensively considering the data sets of these two years, the relationship between $C W C$ and $R S W C$ was significant, but $R S W C$ could explain only $4.2 \%$ of the variation in $C W C$. However, $R S W C$ determined $28.9 \%$ of the variation in $\overline{E W T}$ and $\overline{E W T}$ explained $21.7 \%$ of $C W C$. $C W C-R S W C$ obviously exhibited a two-dimensional trapezoid space (Figure 5). This indicated that the pixels of crops that had been well-supplied with water and well-developed could reach the upper-right positions of this space. Although the maize plants were at the peak of growth, the plants were restricted by water deficiency. That is, $C W C$ was also affected by crop developmental stages if crops were well-supplied with water (Figure 5). CWC was affected by both the stage of crop growth and development as well as by soil water conditions, and was located in the two dimensional coordinates of $C W C-R S W C$. In the $C W C-R S W C$ two-dimensional trapezoidal space, the 2013 data sets with plants that were well-supplied with water and were well-developed lay in the upper-right of that space. The 2014 data sets had relatively less water and were more poorly-developed; these were located in the lower-left of the trapezoidal space (Figure 5). The sensitivity of $C W C$ to the variation of soil water conditions was weakened because of the regulation of crop growth and development. In fact, the variation information related to $C W C$ was an important biophysical property and was relatively easy to be monitored by remote sensing information. This study showed that the relationship between $\overline{E W T}$ and $R S W C$ was relatively stable, and $R S W C$ could explain $23.5 \%-28.9 \%$ of the variation in $\overline{E W T}$, although the $C W C-\overline{E W T}$ relationship varied with inter-annual water condition 
status. The $C W C-\overline{E W T}$ relationship was weaker in a drier year, and there was no significantly linear relationship between $C W C$ and $\overline{E W T}$ in the drier year of 2014.
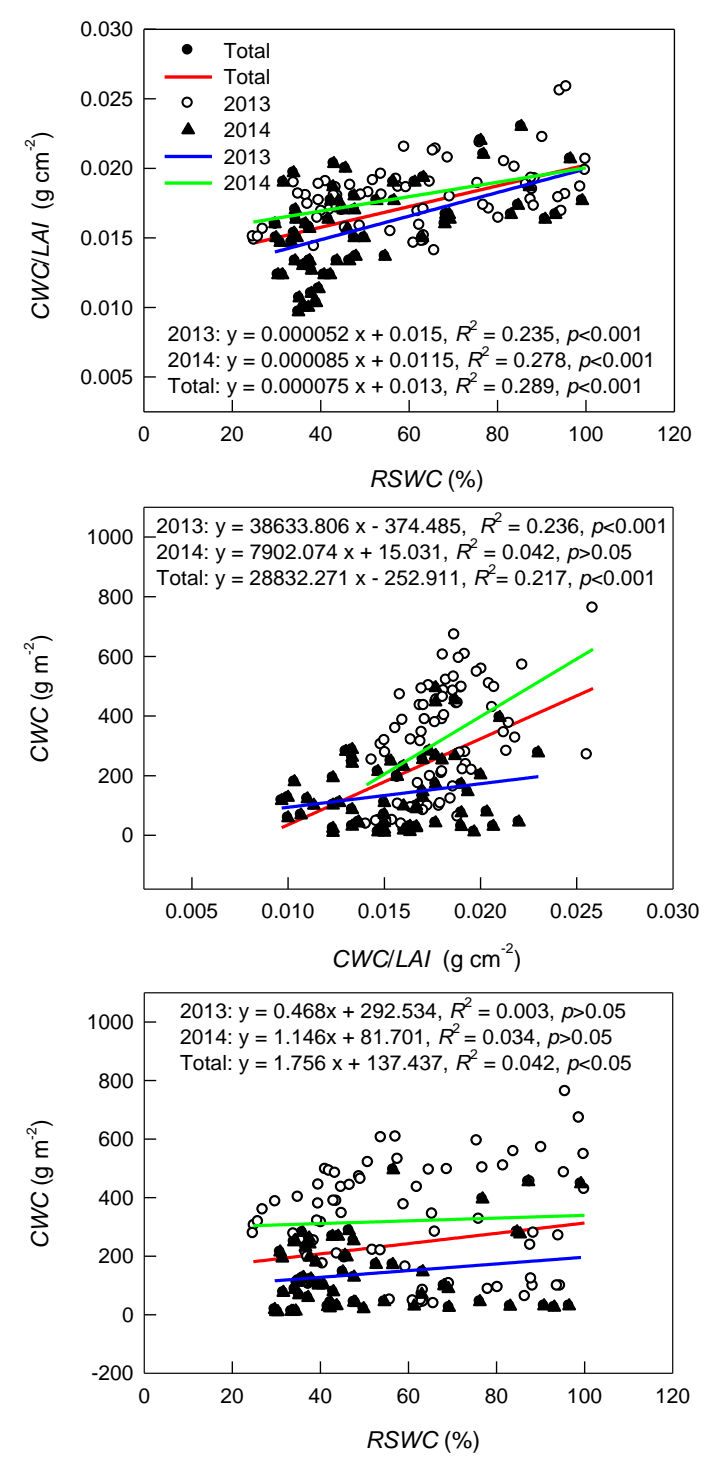

Figure 5. Relationships between $C W C, \overline{E W T}$ (CWC/LAI), and $R S W C$ for maize during the growing seasons of 2013-2014. Figure 2 provides the definitions of acronyms.

\subsection{Effects of Different Years on the Relationships between VIs with CWC and $\overline{E W T}$}

Studies of the relationships between VIs with $C W C$ and $\overline{E W T}$ showed that in 2013 the most sensitive

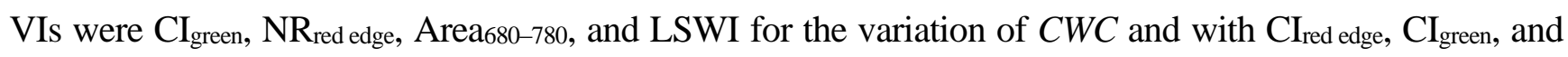
$\mathrm{NR}_{\text {red edge }}$ for the variation of $\overline{E W T}$. In 2014, the most sensitive VIs were $\mathrm{CI}_{\text {green, }} \mathrm{NR}_{\text {red edge, }}$ Area680-780, and LSWI for $C W C$ and $\mathrm{CI}_{\text {red edge, }} \mathrm{CI}_{\text {green, }}$ and NRred edge for $\overline{E W T}$. In addition, the most sensitive VIs were CIgreen, NR red edge, Area680-780, and CIred edge for $C W C$ and $\mathrm{CI}_{\text {red edge, }} \mathrm{CI}_{\text {green, and NR }}$ red edge for $\overline{E W T}$ when comprehensively considering both years. Therefore, at an inter-annual scale, different water control conditions did not affect the sensitivity of VIs to the variations of $C W C$ and $\overline{E W T}$. Moreover, the differences of crop development resulted in stretching of $C W C$ gradients. Therefore, the VIs-CWC relationships were more closely related. In this study, different irrigation treatments led to a wide range variation of $C W C$, including not only the well-developed crop canopy in the field control and the plot 
control under well-supplied rainfed conditions, but also the less-developed crop canopy with dry and bare soils in drought-simulated conditions. In comparison, the relationships between $C W C$ with CIgreen, CIred edge and NRred edge, as well as $\overline{E W T}$ with $\mathrm{CI}_{\text {green, }} \mathrm{CI}_{\text {red edge }}$ and NR red edge in both 2013 and 2014 showed that the linear relationships in 2013 were more similar to that of 2013 plus 2014. Meanwhile, the

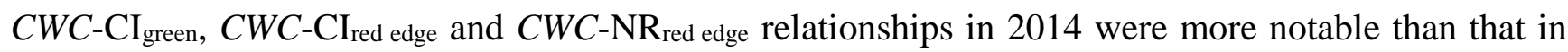
2013. In contrast, the $\overline{E W T}$-CIgreen, $\overline{E W T}$-CIred edge and $\overline{E W T}$-NR red edge relationships in 2013 were more closely related than those in 2014 (Figure 6). In addition, to some extent, Figure 6 shows that when CIgreen was compared with $\mathrm{CI}_{\text {red edge }}$ and $\mathrm{NR}_{\text {red edge, }} \mathrm{CI}_{\text {green }}$ was not affected by different soil moisture conditions and different crop growth status. These differences resulted from the differences in soil water content, and more stably reflected the variation of $C W C$. However, CIred edge was the best sensitivity index for the variation of $\overline{E W T}$ when compared with $\mathrm{CI}_{\text {green }}$ and $\mathrm{NR}_{\text {red edge. }}$
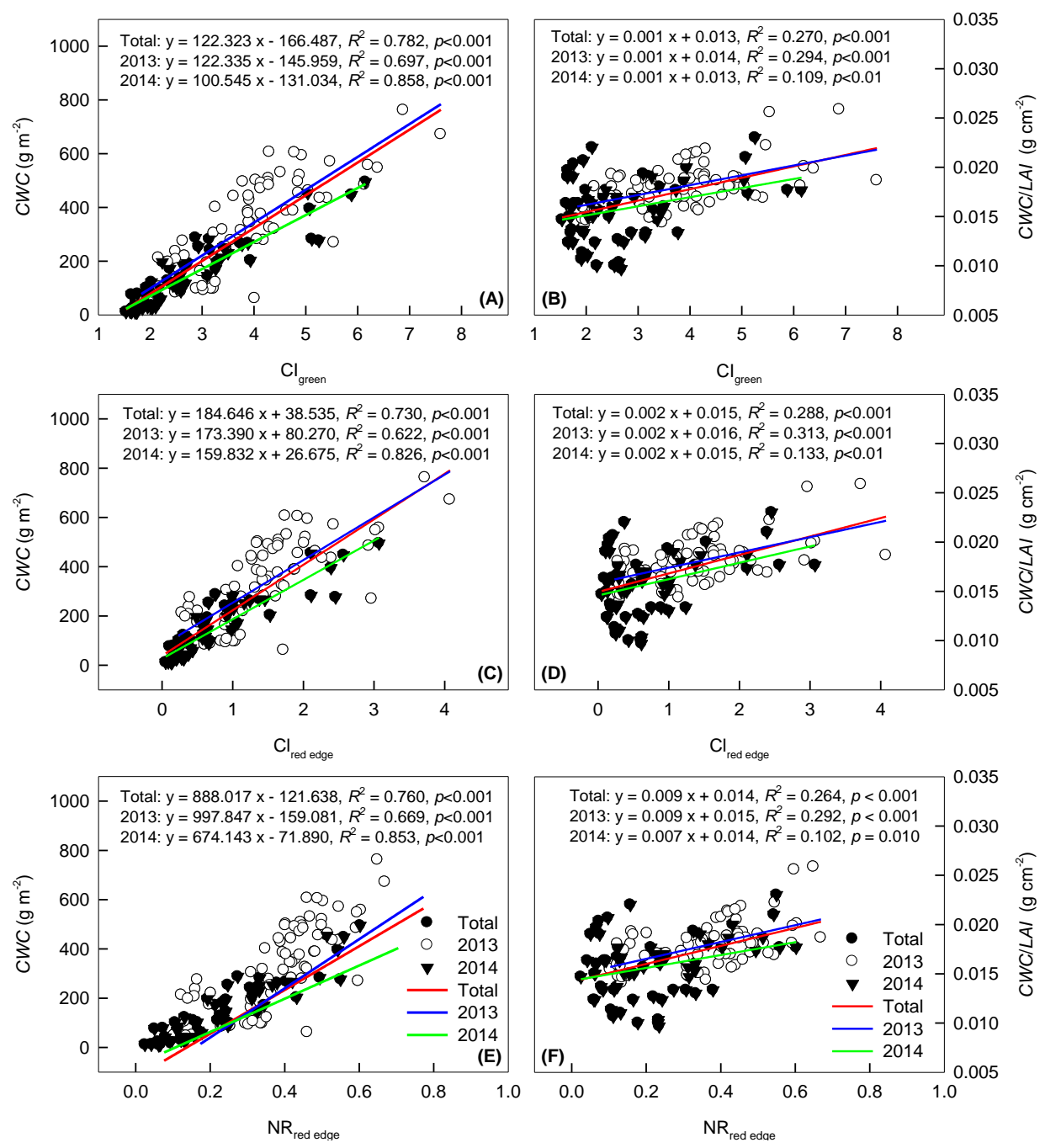

Figure 6. Relationships between $C W C$ and $\overline{E W T}(C W C / L A I) v s$. $\mathrm{CI}_{\text {green }}, \mathrm{CI}_{\text {red edge, and }}$

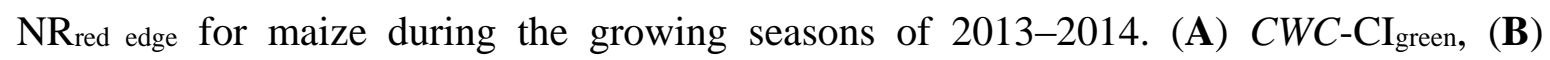
$\overline{E W T}-\mathrm{CI}_{\text {green, }},(\mathbf{C}) C W C-\mathrm{CI}_{\text {red edge, }}$ (D) $\overline{E W T}-\mathrm{CI}_{\text {red edge, }}(\mathbf{E}) C W C$-NR $\mathrm{NR}_{\text {red edge, }}$ and $(\mathbf{F})$

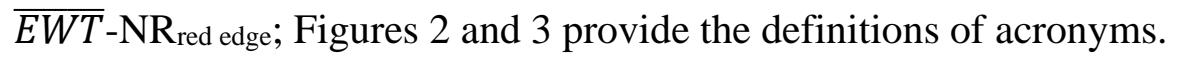




\subsection{Performance of Various Indices for Indicating CWC and $\overline{E W T}$}

Based on the wide variation in $C W C$ and $\overline{E W T}$ and the corresponding observational datasets of their canopy reflectance spectra, the present study investigated the sensitivities of VIs to $C W C$ and $\overline{E W T}$. The results showed that among the ten VIs tested, the most sensitive VIs were: $\mathrm{CI}_{\text {green }}>\mathrm{NR}_{\text {red edge }}>\mathrm{Area}_{680-780}>\mathrm{CI}_{\text {red edge }}$

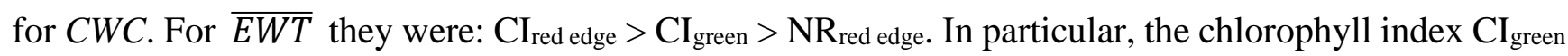
was the best suited for $C W C$ estimation although $\mathrm{CI}_{\text {red edge }}$ was the best predictor for $\overline{E W T}$ retrieval. In this study, the $\mathrm{CI}_{\text {red edge }}$ was slightly less effective than $\mathrm{CI}_{\text {green }}$ when estimating $C W C$. In contrast, it was better than $\mathrm{CI}_{\text {green }}$ when assessing $\overline{E W T}$, but their predictive powers were also better. In view of the calculating equation, the algorithm for $\mathrm{CI}_{\text {green }}$ is retrieved from the contrast of near-infrared and green information, and is calculated by the following equation $\left(\rho_{750} / \rho_{550}\right)-1$. However, the $\mathrm{NR}_{\text {red edge }}$ was calculated as $\left(\rho_{750}-\rho_{710}\right) /\left(\rho_{750}+\rho_{710}\right)$ and is based on near-infrared and red edge information. In addition, $\mathrm{CI}_{\text {red edge }}$ and NRred edge were actually based on the same spectral information, with a longer spectral domain $(750 \mathrm{~nm})$ and shorter range $(710 \mathrm{~nm})$ in red edge region; they only had different algorithm formations. Studies have shown that empirical models used for the prediction of chlorophyll content are largely based on the reflectance at near $550 \mathrm{~nm}$ or $700 \mathrm{~nm}$ where higher chlorophyll content is required to saturate the absorption wavelength. Therefore, indices formulated with these bands had better estimation accuracy [21]. That is, when spectral information around $750 \mathrm{~nm}$ remained consistent, reflectance near $550 \mathrm{~nm}$ in the green region and red edge region at $710 \mathrm{~nm}$ were more difficult to saturate at the absorption wavelength than reflectance around $680 \mathrm{~nm}$. Therefore, VIs based on these spectral data could effectively improve the accuracy for the estimate of chlorophyll, LAI and biomass [21]. Viña et al. [15] showed that $\mathrm{CI}_{\text {red edge }}$ was the only index that was not sensitive to crop type (maize and soybean) among the indices they tested (CIgreen, CIred edge, and the MERIS Terrestrial Chlorophyll Index). Therefore, it was a suitable and accurate index for the remote estimation of green

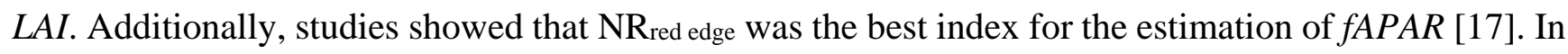
fact, studies usually showed that when estimating vegetation canopy biophysical properties the

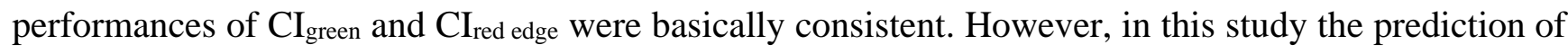
$\mathrm{CI}_{\text {green }}$ for $C W C$ was better than that of $\mathrm{CI}_{\text {red edge }}$ (Figure 7). Although the sensitivities of $R_{710}$ to the variations of $C W C$ and $\overline{E W T}$ were more obvious than those of $R_{550}, \mathrm{CI}_{\text {green }}$ was still the most suitable index for estimating $C W C$ (Figure 7). In addition, $\mathrm{CI}_{\text {red edge }}$ was the most sensitive index for retrieving $\overline{E W T}$. This study demonstrated that the chlorophyll indices $\mathrm{CI}_{\text {green }}$ and $\mathrm{CI}_{\text {red edge }}$ and the normalized index (NR $\mathrm{NR}_{\text {redge }}$ ) were good predictors of both $C W C$ and $\overline{E W T}$.

Water exhibits a number of absorption features in the wavelengths of optical radiation, notably around 970,1200, 1450, and $1950 \mathrm{~nm}$. Among them, the features at 1450 and $1950 \mathrm{~nm}$ are the most pronounced. However, strong water vapor absorption in the atmosphere reduces the effectiveness of these spectral information to essentially zero [6,44]. Studies have been conducted on the remote estimation of $C W C$ using first derivative reflectance spectra, spectral reflectance indices, and continuum removed spectra analysis. However, this study tried to concentrate on whether the normalized reflectance curve area index was suitable for estimating $C W C$ and $\overline{E W T}$. Ren et al. [41] showed that the performance of the normalized red-edge reflectance curve area in the $680-780 \mathrm{~nm}$ region was better when used to estimate green aboveground biomass in arid and semi-arid areas. In this study, gradient irrigation treatments resulted in different levels of drought stress. The crop canopy appeared to be sparse 
and less-developed; therefore, here we introduced Area680-780 and tested its performance for estimating a wide range variation of $C W C$ and $\overline{E W T}$. Clevers et al. [6] showed that the derivative of the reflectance on the right slope of the canopy water absorption feature at $970 \mathrm{~nm}$ can best be used for estimating $C W C$. Furthermore, Clevers et al. [25] showed that the first derivative over the 1015-1050 nm interval and the right slope of the $970 \mathrm{~nm}$ water-absorption band can be used for estimating CWC. Based on the algorithm method of Area680-780, this study newly constructed Area1015-1050 and Area1110-1170 on the right and left slopes of the canopy water absorption feature at 970 and $1200 \mathrm{~nm}$, respectively. This study showed that the linear relationship between Area680-780 and CWC was the third best, only being inferior

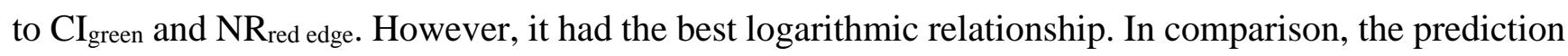
ability of the three area-based VIs for the variation of $C W C$ showed that with increasing $C W C$, the sensitivity was successively greater as expressed best by Area680-780 $>$ Area1015-1050 $>$ Area1110-1170. This result demonstrated that the canopy water information at the red edge of 680-780 nm was more pronounced than that of the right or left slopes of the canopy water absorption feature at $970 \mathrm{~nm}$ or 1200 $\mathrm{nm}$, respectively. Certainly, it is worth noticing that Area680-780 still had a saturated inclination at moderate-high vegetation conditions in the actual application. Ren et al. [41] provides a good example of the reason this occurs, showing that Area680-780 is better in sparsely vegetated conditions. It was also demonstrated that Area680-780 had better predictive power for the variation in $\overline{E W T}$ compared with Area1015-1050 and Area1110-1170 (Figure 4). However, this study still indicated that the normalized reflectance curve area indices were actually more suited for estimation of biomass or $L A I$ rather than $\overline{E W T}$.
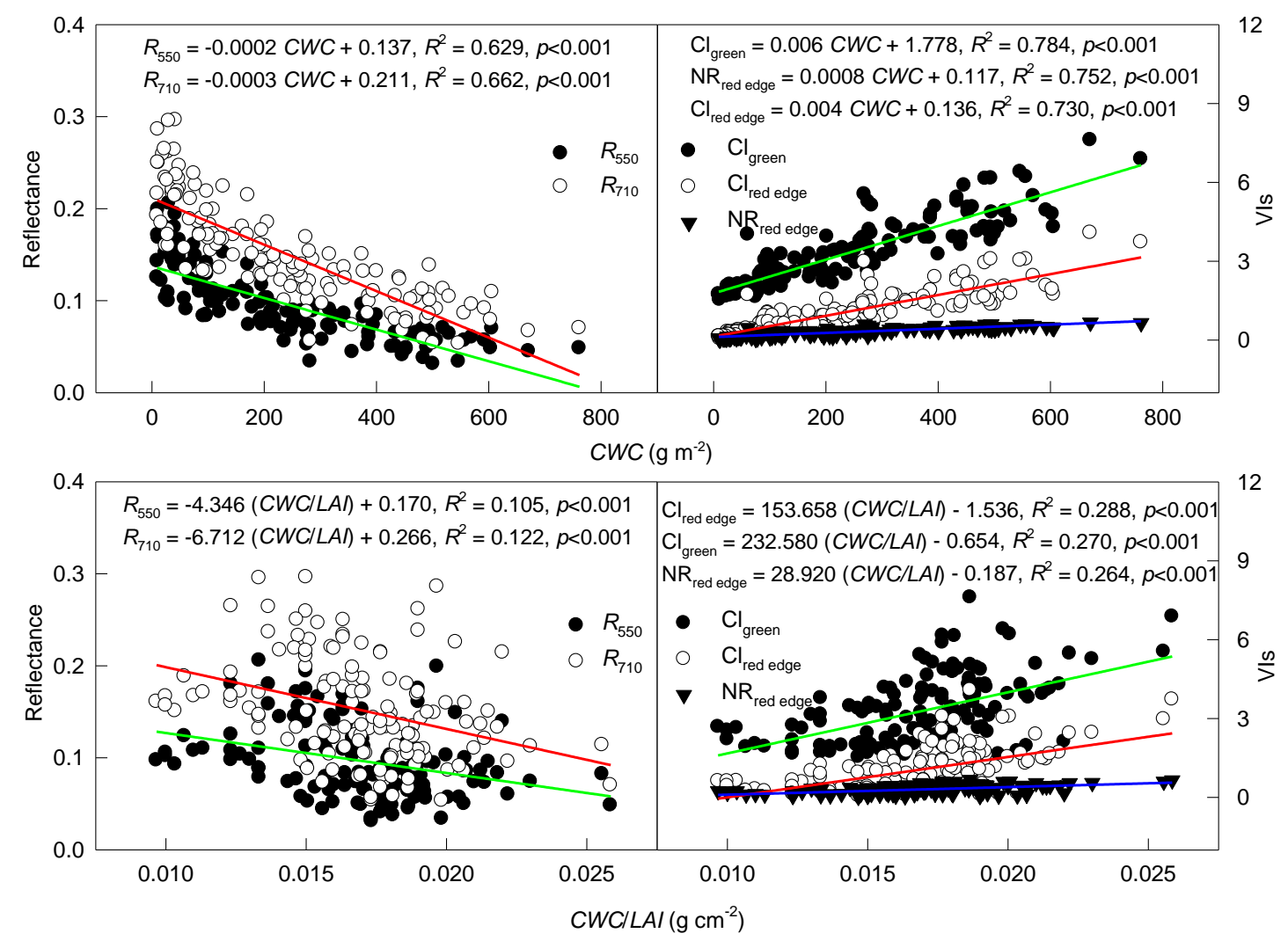

Figure 7. Relationships between $C W C$ and $\overline{E W T}(C W C / L A I) v s$. reflectance $\left(R_{550}\right.$ and $\left.R_{710}\right)$ and $C W C$ and $\overline{E W T}$ (CWC/LAI) vs. VIs ( $\left.\mathrm{CI}_{\text {green, }} \mathrm{CI}_{\text {red edge, and }} \mathrm{NR}_{\text {red edge }}\right)$ for maize during the growing seasons of 2013-2014. Figures 2 and 3 provide the definitions of acronyms. 
This study was a new exploration of the chlorophyll indices ( $\mathrm{CI}_{\text {green }}$ and $\left.\mathrm{CI}_{\text {red edge }}\right)$ and the normalized index (NR red edge). We tested to see whether the chlorophyll indices and NRred edge that had previously proved to be well suited for monitoring chlorophyll content, LAI, fAPAR, and biomass could perform well when monitoring vegetation status and stress, especially in relation to water stress, and allow us to obtain satisfactory results. Eventually, this study revealed that the cause of the saturation effects of VIs in relation to the variation of $C W C$ at middle to high vegetation conditions was the effects of $L A I$, but not because of the effects of water information. Moreover, this study also showed that $\mathrm{CI}_{\text {green }}$ could explain $78.4 \%$ of the variation in $C W C$ and only $27.0 \%$ of variation in $\overline{E W T}$, i.e., CWC/LAI. In addition, CIred edge explained $73.0 \%$ of the variation in $C W C$ and $28.8 \%$ of variation in $\overline{E W T}$, and NR red edge explained $75.3 \%$ of $C W C$ and $26.4 \%$ of $\overline{E W T}$, which demonstrated that around $44.2 \%-51.4 \%$ of the variation in $C W C$ explained by spectral information was derived from the variation in $L A I$. It is well known that $L A I$ and $C W C$ are very highly correlated, this study emphasized again that $L A I$ determined most of the variation in $C W C$.

\section{Conclusions}

In this study, the performances of ten water content related VIs were examined when used to estimate $C W C$ and $\overline{E W T}$. We found that: (1) ten VIs showed great sensitivity to a wide range of variation in $C W C$, and indicated relatively weak sensitivity to the variation in $\overline{E W T}$; (2) the chlorophyll indices ( $\mathrm{CI}_{\text {green }}$ and $\left.\mathrm{CI}_{\text {red edge }}\right)$ and the normalized index ( $\left.\mathrm{NR}_{\text {red edge }}\right)$ were the most sensitive VIs to the variations in $C W C$ and $\overline{E W T}$; (3) simulated drought under in situ conditions in two differently managed irrigation years did not distinctly affect the sensitivity of VIs to the variations of $C W C$ and $\overline{E W T}$; however, the degree of correlation for the relationship models changed; and (4) the $C W C$ - $R S W C$ two-dimensional trapezoidal space clearly revealed that $C W C$ was not only closely related with soil water status but also was determined by crop growth and development stages; and (5) nearly half of the variation in $C W C$ explained by spectral information was derived from the variation in $L A I$.

Inevitably, crop canopy biophysical properties were obviously interrelated. However, estimation of $C W C$ using hyperspectral remote sensing data was determined by spectral information from three aspects of crop growth: crop greenness (chlorophyll), canopy architecture (LAI) and $\overline{E W T}$. Therefore, in the future, when constructing models for estimating $C W C$, we should not only take into account spectral information sensitivity to the variation of canopy greenness and $\overline{E W T}$, but also understand the stages of crop growth and development.

\section{Acknowledgements}

This research was supported by National Natural Science Foundation of China (41330531). We acknowledge Gucheng Ecological and Agricultural Meteorology Station, Chinese Academy of Meteorological Sciences for providing convenient experiment facilities. We thank Juntun Zhang from Beijing Normal University for his fruitful discussion and Zhenzhu Xu for his critical suggestions. We also thank Yanling Jiang, Xueyan Ma, Yaohui Shi, Huailin Zhou, Minzheng Wang, Qiuling Wang, Yuhe Ji, Tao Liu, and Jun Tang for their help during field work. We are grateful to the editors and anonymous reviewers for their constructive comments on the earlier version of the manuscript. 


\section{Author Contributions}

Guangsheng Zhou and Feng Zhang conceived and designed the research; Feng Zhang performed the experiments; Feng Zhang and Guangsheng Zhou analyzed the data and wrote the manuscript.

\section{Conflicts of Interest}

The authors declare no conflicts of interest.

\section{References}

1. Carter, G.A. Responses of leaf spectral reflectance to plant stress. Am. J. Bot. 1993, 80, 239-243.

2. Peñuelas, J.; Gamon, J.A.; Fredeen, A.L.; Merino, J.; Field, C.B. Reflectance indices associated with physiological changes in nitrogen and water limited sunflower leaves. Remote Sens. Environ. 1994, 48, 135-146.

3. Stimson, H.C.; Breshears, D.D.; Ustin, S.L.; Kefauver, S.C. Spectral sensing of foliar water conditions in two co-occurring conifer species: Pinus edulis and Juniperus monosperma. Remote Sens. Environ. 2005, 96, 108-118.

4. Peñuelas, J.; Filella, I.; Biel, C.; Serrano, L.; Save, R. The reflectance at the 950-970 nm region as an indicator of plant water status. Int. J. Remote Sens. 1993, 14, 1887-1905.

5. Yi, Q.; Wang, F.; Bao, A.; Jiapaer, G. Leaf and canopy water content estimation in cotton using hyperspectral indices and radiative transfer models. Int. J. Appl. Earth Obs. 2014, 33, 67-75.

6. Clevers, J.G.P.W.; Kooistra, L.; Schaepman, M.E. Using spectral information from the NIR water absorption features for the retrieval of canopy water content. Int. J. Appl. Earth Obs. 2008, 10, 388-397.

7. Rollin, E.M.; Milton, E.J. Processing of high spectral resolution reflectance data for the retrieval of canopy water content information. Remote Sens. Environ. 1998, 65, 86-92.

8. Running, S.W.; Gower, S.T. Forest-BGC, a general model of forest ecosystem processes for regional applications II. Dynamic carbon allocation and nitrogen budgets. Tree Physiol. 1991, 9 , 147-160.

9. Running, S.W.; Nemani, R.R. Regional hydrologic and carbon balance responses of forests resulting from potential climate change. Climatic Change 1991, 19, 349-368.

10. De Jong, S.M.; Addink, E.A.; Doelman, J.C. Detecting leaf-water content in Mediterranean trees using high-resolution spectrometry. Int. J. Appl. Earth Obs. 2014, 27, 128-136.

11. Ustin, S.L.; Roberts, D.A.; Gamon, J.A.; Asner, G.P.; Green, R.O. Using imaging spectroscopy to study ecosystem processes and properties. BioScience 2004, 54, 523-534.

12. Chuvieco, E.; Rianõ, D.; Aguado, I.; Cocero, D. Estimation of fuel moisture content from multi temporal analysis of Landsat Thematic Mapper reflectance data: Applications in fire danger assessment. Int. J. Remote Sens. 2002, 23, 2145-2162.

13. Yilmaz, M.T.; Hunt, E.R., Jr.; Goins, L.D.; Ustin, S.L.; Vanderbilt, V.C.; Jackson, T.J. Vegetation water content during SMEX04 from ground data and Landsat 5 Thematic Mapper imagery. Remote Sens. Environ. 2008, 112, 350-362. 
14. Gitelson, A.A.; Viña, A.; Arkebauer, T.J.; Rundquist, D.C.; Keydan, G.; Leavitt, B. Remote estimation of leaf area index and green leaf biomass in maize canopies. Geophys. Res. Lett. 2003, 30, doi:10.1029/2002GL016450.

15. Viña, A.; Gitelson, A.A.; Nguy-Robertson, A.L.; Peng, Y. Comparison of different vegetation indices for the remote assessment of green leaf area index of crops. Remote Sens. Environ. 2011, $115,3468-3478$.

16. Nguy-Robertson, A.L.; Peng, Y.; Gitelson, A.A.; Arkebauer, T.J.; Pimstein, A.; Herrmann, I.; Karnieli, A.; Rundquist, D.C.; Bonfil, D.J. Estimating green LAI in four crops: Potential of determining optimal spectral bands for a universal algorithm. Agric. For. Meteorol. 2014, 192, 140-148.

17. Viña, A.; Gitelson, A.A. New developments in the remote estimation of the fraction of absorbed photosynthetically active radiation in crops. Geophys. Res. Lett. 2005, 32, doi:10.1029/2005GL023647.

18. Zhang, F.; Zhou, G.; Nilsson, C. Remote estimation of the fraction of absorbed photosynthetically active radiation for a maize canopy in Northeast China. J. Plant Ecol. 2015, 8, 429-435.

19. Gitelson, A.A.; Viña, A.; Ciganda, V.; Rundquist, D.C.; Arkebauer, T.J. Remote estimation of canopy chlorophyll content in crops. Geophys. Res. Lett. 2005, 32, doi:10.1029/2005GL022688.

20. Wu, C.; Niu, Z.; Tang, Q.; Huang, W. Estimating chlorophyll content from hyperspectral vegetation indices: Modeling and validation. Agric. For. Meteorol. 2008, 148, 1230-1241.

21. Wu, C.; Niu, Z.; Tang, Q.; Huang, W.; Rivard, B.; Feng, J. Remote estimation of gross primary production in wheat using chlorophyll-related vegetation indices. Agric. For. Meteorol. 2009, 149, 1015-1021.

22. Peng, Y.; Gitelson, A.A. Application of chlorophyll-related vegetation indices for remote estimation of maize productivity. Agric. For. Meteorol. 2011, 151, 1267-1276.

23. Zhang, F.; Zhou, G. Estimating canopy photosynthetic parameters in maize field based on multi-spectral remote sensing. Chin. J. Plant Ecol. 2014, 38, 710-719.

24. Colombo, R.; Meroni, M.; Marchesi, A.; Busetto, L.; Rossini, M.; Giardino, C.; Panigada, C. Estimation of leaf and canopy water content in poplar plantations by means of hyperspectral indices and inverse modeling. Remote Sens. Environ. 2008, 112, 1820-1834.

25. Clevers, J.G.P.W.; Kooistra, L.; Schaepman, M.E. Estimating canopy water content using hyperspectral remote sensing data. Int. J. Appl. Earth Obs. 2010, 12, 119-125.

26. Mirzaie, M.; Darvishzadeh, R.; Shakiba, A.; Matkan, A.A.; Atzberger, C.; Skidmore, A. Comparative analysis of different uni- and multi-variate methods for estimation of vegetation water content using hyper-spectral measurements. Int. J. Appl. Earth Obs. 2014, 26, 1-11.

27. Darvishzadeh, R.; Atzberger, C.; Skidmore, A.; Schlerf, M. Mapping grassland leaf area index with airborne hyperspectral imagery: A comparison study of statistical approaches and inversion of radiative transfer models. ISPRS J. Photogramm. Remote Sens. 2011, 66, 894-906.

28. Atzberger, C.; Darvishzadeh, R.; Immitzer, M.; Schlerf, M.; Skidmore, A.; Le Maire, G. Comparative analysis of different retrieval methods for mapping grassland leaf area index using airborne imaging spectroscopy. Int. J. Appl. Earth Obs. 2015, 43, 19-31.

29. Zhang, F.; John, R.; Zhou, G.; Shao, C.; Chen, J. Estimating canopy characteristics of Inner Mongolia's grasslands from field spectrometry. Remote Sens. 2014, 6, 2239-2254. 
30. Atzberger, C.; Guérif, M.; Baret, F.; Werner, W. Comparative analysis of three chemometric techniques for the spectroradiometric assessment of canopy chlorophyll content in winter wheat. Comput. Electron. Agr. 2010, 73, 165-173.

31. Ren, H.; Zhou, G. Estimating aboveground green biomass in desert steppe using band depth indices. Biosyst. Eng. 2014, 127, 67-78.

32. Tan, K.; Zhou, G.; Ren, S. Response of leaf dark respiration of winter wheat to changes in $\mathrm{CO}_{2}$ concentration and temperature. Chin. Sci. Bull. 2013, 58, doi:10.1007/s11434-012-5605-1.

33. Li, B. Maize Drought Process and Its Dynamics Simulation. Master's Thesis, Chinese Academy of Meteorological Sciences, Beijing, China, 2014.

34. Ceccato, P.; Gobron, N.; Flasse, S.; Pinty, B.; Tarantola, S. Designing a spectral index to estimate vegetation water content from remote sensing data: Part 1-Theoretical approach. Remote Sens. Environ. 2002, 82, 188-197.

35. Danson, F.M.; Steven, M.D.; Malthus, T.J.; Clark, J.A. High-spectral resolution data for determining leaf water content. Int. J. Remote Sens. 1992, 13, 461-470.

36. Rouse, J.W.; Haas, R.H., Jr.; Schell, J.A.; Deering, D.W. Monitoring the Vernal Advancement and Retrogradation (Green Wave Effect) of Natural Vegetation; Progress Report RSC 1978-1; Remote Sensing Center, Texas A\&M University: College Station, TX, USA, 1973.

37. Gitelson, A.A.; Merzlyak, M.N. Signature analysis of leaf reflectance spectra: Algorithm development for remote sensing. J. Plant Physiol. 1996, 148, 493-500.

38. Gao, B.C. NDWI-A normalized difference water index for remote sensing of vegetation liquid water from space. Remote Sens. Environ. 1996, 58, 257-266.

39. Jurgens, C. The modified normalized difference vegetation index (mNDVI) - A new index to determine frost damages in agriculture based on Landsat TM data. Int. J. Remote Sens. 1997, 18, 3583-3594.

40. Xiao, X.; Boles, S.; Liu, J.; Zhuang, D.; Frolking, S.; Li, C.; Salas, W.; Moore, B. Mapping paddy rice agriculture in southern China using multi-temporal MODIS images. Remote Sens. Environ. 2005, 95, 480-492.

41. Ren, H.; Zhou, G.; Zhang, X. Estimation of green aboveground biomass of desert steppe in Inner Mongolia based on red-edge reflectance curve area method. Biosyst. Eng. 2011, 109, 385-395.

42. Gitelson, A.A.; Merzlyak, M. Spectral reflectance changes associated with autumn senescence of Asculus hippocastanum and Acer platanoides leaves: Spectral features and relation to chlorophyll estimation. J. Plant Physiol. 1994, 143, 286-292.

43. Gitelson, A.A.; Viña, A.; Verma, S.B.; Rundquist, D.C.; Arkebauer, T.J.; Keydan, G.; Leavitt, B.; Ciganda, V.; Burba, G.G.; Suyker, A.E. Relationship between gross primary production and chlorophyll content in crops: Implications for the synoptic monitoring of vegetation productivity. J. Geophys. Res. 2006, 111, doi:10.1029/2005JD006017.

44. Curran, P.J. Remote sensing of foliar chemistry. Remote Sens. Environ. 1989, 30, 271-278.

(C) 2015 by the authors; licensee MDPI, Basel, Switzerland. This article is an open access article distributed under the terms and conditions of the Creative Commons Attribution license (http://creativecommons.org/licenses/by/4.0/). 